\title{
DNA 骨架磷硫酰化修饰的研究进展
}

\author{
胡中培 $a, b$ 王呈坤 ${ }^{b}$ 蓝文贤 $b$ 李芳 $*, a$ 曹春阳*, $b$ \\ ( ${ }^{a}$ 华中师范大学化学学院 武汉 430079) \\ $\left({ }^{b}\right.$ 中国科学院上海有机化学研究所生命有机化学国家重点实验室 上海 200032)
}

\begin{abstract}
摘要 DNA 骨架磷硫酰化修饰是指在天然 DNA 骨架上发现的 $\mathrm{P}-\mathrm{O}$ 键被 $\mathrm{P}-\mathrm{S}$ 键替换的化学修饰, 属于首例生理修饰, 具有磷硫修饰的 DNA 在 Tris 缓冲体系中电泳时具有 DNA 降解表型. 研究发现 DNA 骨架磷硫修饰属于复制后修饰, 具 有如下三个特征: $R_{p}$ 型立体修饰, 序列专一性、分布广泛性. 这种修饰由五个基因组成的 $d n d$ 基因簇( $(n d A-E)$ 编码的蛋 白控制, 但这些蛋白具体的作用机制目前还不清楚. 为了将来更好地研究 DNA 磷硫修饰机制, 本文综述了 DNA 磷硫 酰化修饰的发现历程, 特点, 参与 DNA 磷硫修饰的蛋白结构研究进展, 以及磷硫修饰的 DNA 作为抗氧化剂研究进展. 同时，对 DNA 磷硫修饰机制、生理功能等研究目前所面临的困难，如硫原子如何渗入 DNA 骨架，参与 DNA 磷硫修饰 的五个蛋白是如何协调作用完成 DNA 磷硫修饰的机理等难题进行了简单概括, 以为相关研究提出一些可能的方向. 关键词ＤNA; 磷硫酰化; DndA-E; Dnd 表型; 综述
\end{abstract}

\section{Recent Advances in DNA Phosphorothioation Modification Studies}

\author{
Hu, Zhongpe ${ }^{a, b} \quad$ Wang, Chengkun $^{b} \quad$ Lan, Wenxian $^{b} \quad$ Li, Fang* ${ }^{* a} \quad$ Cao, Chunyang*, \\ $\left({ }^{a}\right.$ College of Chemistry, Central China University, Wuhan 430079) \\ ( ${ }^{b}$ State Key Lab of Bio-organic and Natural Products Chemistry, Shanghai Institute of Organic Chemistry,
}

Chinese Academy of Sciences, Shanghai 200032)

\begin{abstract}
DNA phosphorothioate (PT) modification is a sulfur modification on DNA backbone, in which a non-bridging $\mathrm{P}-\mathrm{O}$ bond is changed into a non-bridging P-S bond, being the first physiological modification described on the DNA backbone. It is found that the DNA with backbone phosphoration has DNA degradation (Dnd) phenotype upon running electrophoresis in Tris buffer. Moreover, this DNA phosphorothioation belongs to a kind of post-replication modification, where sulfur is incorporated stereo-specifically (i.e., it's a chiral $R_{p}$-type modification, not $S_{p}$-type configuration) into DNA backbone at specific sequences. For example, a high frequency of GA was found to be phosphorothioated in Bermanella marisrubri RED65 and Hahella chejuensis KCTC2396, determined by using high pressure or high performance liquid chromatography (HPLC) and mass methods. DNA phosphorothioation is widespread and quantized in bacterial genomes. It was reported that this DNA PT modification is controlled by the five proteins (DndA-E) encoded by dna degradation (dnd) genes cluster $(d n d A-E)$ in a sequence found in bacteria and archaea, but the mechanism about how these five proteins function during the pathway of DNA backbone PT modification remains elusive. Among these five genes, four of them, $d n d A$ and $d n d C-E$, are essential for the PT modification, while inactivation of $d n d B$ resulted in increased phosphorothioation and altered sequence preference. In this paper, we reviewed the discovery history, the features of DNA phosphorothioation modification, and the recent research progresses on the structures and functions of the five proteins involved in DNA backbone phosphorothioation. We also discussed the antioxidant activities of phosphorothioated DNA in biological systems. Finally, for easily understanding the research direction in DNA phosphorothioation, we summarized several questions in the future studies on DNA PT modification, which includes: (1) How sulfur is incorporated into DNA backbone in biological system? (2) How the DNA phosphorothioation is affected by the proteins DndA, DndB, DndC, DndD and DndE? (3) How to get soluble DndB, DndC and DndD in a large quantity? (4) How DndA functions as a cysteine sulfur transferase, because the active site is in a rigid $\beta$ sheet conformation?

Keywords DNA; phosphorothioate; DndA-E; Dnd phenotype; review
\end{abstract}

\section{1 引言}

众所周知 DNA 是遗传信息的载体, 在 DNA 上发生 各种化学修饰都能够引起遗传信息的变化. DNA 的结构
修饰在生命进化过程中起着十分重要的作用 ${ }^{[1]}$, 研究 DNA 结构修饰是当今研究热点之一.

研究发现, 在 DNA 上存在多种类型的化学修饰, 总体上可以分为两类: 一类是发生在 DNA 的碱基上,

*E-mail: f.li@mail.ccnu.edu.cn; ccao@mail.sioc.ac.cn

Received December 31, 2012; published February 6, 2013.

Project supported by the National Basic Research Program of China (Nos. 2009CB918600, 2011CB966300) and the National Natural Science Foundation of China (Nos. 20905074, 21272261).

项目受国家科技部重大研究计划(Nos. 2009CB918600, 2011CB966300)和国家自然科学基金(Nos. 20905074, 21272261)资助. 
一类是发生在 DNA 的骨架上. 第一类修饰在生物体内 广泛存在, 人们的研究也比较透彻, 其中最为著名的就 是 1965 年在细菌中发现的 DNA 碱基甲基化修饰. 这种 修饰一方面可以被生物体用来进行自身 DNA 标记, 以 区别外来 DNA, 从而限制其入侵, 以保证生物遗传的稳 定性; 另外一方面在调节基因表达、基因沉默等方面对 分子生物学的发展起到里程碑式的贡献 ${ }^{[2]}$. 第二类修饰 最常见的是 DNA 磷硫酰化修饰(DNA phosphorothioate modification), 最初只是一种人工修饰, 用于修饰寡核 苷酸(oligodeoxynucleotides), 以稳定其结构, 防止被核 酸酶降解 ${ }^{[3]}$.

一直以来，第二类修饰是人工合成 DNA 的产物. 2007 年我国科学家邓子新院士与英、美科学家 ${ }^{[4]}$ 合作, 在变铅青链霉菌(Streptomyces lividans)DNA 骨架上, 发 现了天然的磷硫酰化修饰. 这是对 DNA 结构修饰的又 一补充 ${ }^{[2]}$, 可以证实这种修饰属于生物体内限制修饰体 系, 但具体功能还不清楚 ${ }^{[5]}$. 目前有关 DNA 磷硫修饰的 研究, 相关综述, 尤其是结合当前蛋白质结构研究的综 述基本没有. 为了使科研工作者对 DNA 磷硫修饰机制 能够进一步更好地研究, 本文力图对近年来 DNA 磷硫 酰化的研究进展作一个简明的介绍.

\section{2 磷硫酰化 DNA 的表型与特征}

\subsection{Dnd 表型}

1988 年周秀芬等 ${ }^{[6,7]}$ 在研究变铅青链霉菌 66(Streptomyces lividans 66)基因组 DNA 电泳时候, 发 现该基因组 DNA 在普通凝胶电泳或者脉冲场凝胶电泳 实验中出现降解现象(如图 1). 通过反复试验, 最终排除 了这一现象是受核酸酶污染或人为误差引起的. 这种现 象被命名为 Dnd 表型(DNA degradation phenotype). 进 一步研究发现这种 Dnd 表型有以下特点 ${ }^{[8 \sim 11]}$ : (1)在 Tris 存在的情况下, 普通凝胶电泳或者梯度电泳均会发生 Dnd 现象; (2) Dnd 现象不受甲醛、蛋白酶 K、溶菌酶抑 制; (3)若在电泳缓冲液中加入少量还原性试剂, 尤其是 含硫试剂如硫艮, 或者将 Tris 缓冲液换成 HEPES 缓冲 液, Dnd 现象均可得到抑制.

\section{2 磷硫酰化修饰 DNA 的特点}

\subsubsection{DNA 磷硫酰化修饰具有立体选择性}

王连荣等 ${ }^{[4,12]}$ 通过对降解的 DNA 片段进行高效液 相色谱(HPLC)及液相色谱一质谱(LS-MS)联用技术进行 分析, 发现在降解的 DNA 片段中含有硫元素. 此外通 过 $\left[{ }^{35} \mathrm{~S}\right]-\mathrm{Na}_{2} \mathrm{SO}_{4}$ 放射性硫元素的喂养也证实了有硫元素 参与 Dnd 表型. 进一步的研究证实硫元素渗入到 DNA 骨架当中, 从而使 DNA 电泳时候产生 Dnd 表型, 这种 现象被称为 DNA 磷硫酰化 ${ }^{[6]}$.

随后，他们又对磷硫酰化修饰以后的 DNA 骨架构 象作进一步的研究. 首先发现在微生物体内这种磷硫酰

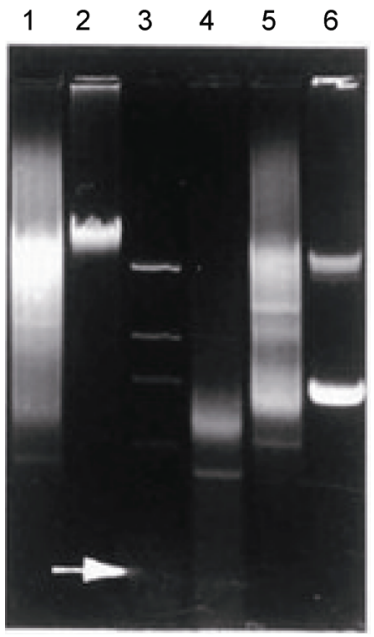

图 1 变铅青链雼菌 DNA 的特异性降解(Dnd 表型) $)^{[5]}$

泳道 1 和泳道 4 是从变铅青链雱菌 66 制备的总 DNA, 含有 $6.2 \mathrm{~kb}$ 大小的 质粒; 泳道 2 是从天蓝链霓菌( streptomyces coelicolor) 制备的总 DNA; 泳 道 3 是用 HindIII 酶切的 $\lambda$ DNA，箭头指向 $2.3 \mathrm{~kb}$ 的片段; 泳道 5 是从 $S$. lividans 66 制备的总 DNA，含有 $6.8 \mathrm{~kb}$ 大小的质粒; 泳道 6 是从大肠杆菌 (Escherichia coli) 制备的总 DNA 含有 $9.6 \mathrm{~kb}$ 的质粒. 泳道 $1 、 4 、 5$ 可以看 到明显的降解拖尾现象(Dnd 表型)

Figure 1 Specific degradation of S. lividans DNA

Lanes 1 and 4, total DNA preparation from $S$. lividans 66 containing a $6.2 \mathrm{~kb}$ plasmid; lane 2, total DNA from $S$. coelicolor A3(2); lane 3, lambda DNA digested with HindIII (the arrow points to the $2.3 \mathrm{~kb}$ fragment); lane 5, total DNA from $S$. lividans 66 containing a $6.8 \mathrm{~kb}$ plasmid; lane $6,9.6 \mathrm{~kb}$ plasmid isolated from $E$. coli. We can see the significant degradation phenomenon (Dnd phenotype)

二核苷结构会被磷脂酶水解裂开，从而得不到这种结 构. 通过多种尝试，他们最终发现三种酶能够抑制磷脂 酶水解磷硫酰的活性, 使磷硫酰二核苷结构得以稳定, 从而最终实现磷硫酰化 DNA 化学结构的鉴定 ${ }^{[2]}$. 结果 为, 大肠杆菌 (Escherichia coli) B7a, DH10B (pJTU1238) 中的骨架磷硫修饰的 DNA 分子, 通过磷脂酶立体选择 性水解，脱磷酸化，产生含硫修饰位点的只有两个核苷 的样品, 利用 HPLC 进行考察, 发现它们与合成标准品 中的 $R_{p}$ 空间构象 5'- $\mathrm{d}\left(\mathrm{G}_{\mathrm{PS}} \mathrm{A}\right)-3^{\prime}$ 具有一致的保留时间, 一 致的紫外吸收特征和质谱信号. 基于这些证据, 又对大 肠杆菌 B7a, DH10B(pJTU1238)中的硫修饰 DNA 分子与 $R_{p}$-型及 $S_{p}$-型的合成标准品 $5^{\prime}-\mathrm{d}\left(\mathrm{G}_{\mathrm{PS}} \mathrm{A}\right)-3^{\prime}$ 进行了高精度 的四级质谱断裂分析, 发现特异性发生在 5'-d(GA)-3'之 间. 最终确定了硫修饰的化学实质是 DNA 骨架发生磷 硫酰化形成硫代磷酸二脂键, 并以专一性的 $R_{p}$ 空间构 象(如图 2)存在.

\subsubsection{DNA 磷硫酰化修饰具有序列选择性}

序列选择性, 是指在变铅青链霉菌中, DNA 磷硫酰 化修饰一般发生在区域 5'-c-cGGCCgccg-3'中高度保守 的具有回型对称特征的核心区 GGCC 的两个 GG 之间. DNA 磷硫修饰序列选择性在不同微生物菌种中表现有 所不同，如在大肠杆菌 B7a 和沙门氏菌(Salmonella spp) 中, 选择性序列不是变铅青链霉菌中的 5'-d(GpsG)-3', 而为 5'-d(GpsA)-3', 对应的碱基序列为: 5'-AG(PS)AAC- 


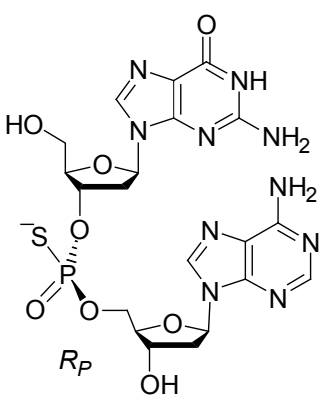<smiles>O=P(O)(O)OCCO</smiles>

图 2 DNA 磷硫酰化的化学本质

DNA 骨架发生磷硫酰化成硫代磷酸二脂键, 并以专一性的 $R_{p}$ (左)空间构 象存在，而非 $S_{p}$ 型(右)

Figure 2 The chemical nature of DNA PT modification

The presence of a sulfur atom in the sugar-phosphate backbone, most likely stereoselective for the $R_{p}$ configuration (left), but not the $S_{p}$ configuration (right)

TGCGC-3' ${ }^{[4,7,13 \sim 15]}$. 通过对多个物种的 DNA 磷硫酰化 修饰进行定量分析表明, DNA 磷硫酰化修饰的位点和频 率均有所不同 ${ }^{[16]}$.

\subsubsection{DNA 磷硫酰化修饰是一种复制后修饰}

依据修饰发生的时间，可以将碱基修饰分为复制前 修饰和复制后修饰 ${ }^{[12]}$. 所谓复制前修饰, 指的是修饰发 生在单核苷酸水平, 在 DNA 复制过程中, 修饰基团通 过 DNA 聚合酶掺入到新生链中 ${ }^{[17]}$. 所谓复制后修饰, 指的是修饰发生在多聚核苷酸水平，一些特异的蛋白酶 可以对碱基进行酶促修饰. 细菌中经典的甲基化修饰就 是这种类型. 这种修饰方式的修饰部位其序列往往具有 特殊性, 这是由修饰酶(如甲基化酶)对 DNA 的序列特 异性要求决定的 ${ }^{[18]}$.

1998 年, Dyson 等 ${ }^{[19]}$ 经过研究探索, 提出 DNA 磷硫 酰化修饰可能为复制后修饰, 原因主要体现在两个方 面：其一，这种修饰的发生不仅需要保守的中心序列， 还依赖于一定长度的侧翼序列和可能的二级结构; 其 二, 质粒复制中间体的单链不能被 Tris 过酸衍生物切 割, 这意味着可能不存在修饰位点, 因为被修饰的双链 DNA 即使变性成单链 DNA 后仍然具有被切割的特性.

\subsubsection{DNA 磷硫修饰具有广泛性}

除了变铅青链霉菌以外, DNA 磷硫修饰的现象在其 他微生物中也存在, 主要包括荧光假单胞菌 (Pseudomonas fluorescens), 铜绿假单胞菌(Pseudomonas aeruginosa), 大肠杆菌 (Escherichia coli), 克氏肺炎杆菌 (Klebsiella pneumoniae), 阴沟肠杆菌(Enterobacter cloacae), 粘质沙雷氏菌(Serratia marcescens), 不动杆菌 (Acinetobacter spp), 沙门氏菌(Salmonella spp), 艰难梭 状芽孢杆菌(Clostridium difficile), 肉毒梭状芽孢杆菌 (Clostridium botulinum), 包皮垢分枝杆菌 (Mycobacterium smegamatis), 呋啶霉素链霉菌 (Streptomyces acrimycini) 和肠炎弧菌(Vibrio parahaemolyticus $)$ 等菌株 ${ }^{[2,20 \sim 25]}$.
另外，某些海洋环境 DNA 样本中也发现了与 $d n d$ 同源的基因，暗示 DNA 骨架磷硫修饰可能在海洋微生 物中也普遍存在. 在已测序的几种代表性细菌 DNA 中, dnd 基因簇的结构和排列非常类似，这一点也暗示了 DNA 骨架磷硫修饰是一种比较普遍的现象 ${ }^{[2]}$.

\section{3 硫元素的渗入通过 dnd 基因控制}

周秀芬等 ${ }^{[7]}$ 通过化学诱导试剂突变, 紫外照射以及 基因敲除等手段证实, Dnd 表型是由 $d n d$ 基因(DNA degradation gene)控制的. $d n d$ 基因定位在一段 $8 \mathrm{~kb}$ 的 DNA 序列上，由 5 个成簇排列的基因组成，分别被命名 为 $d n d A B C D E$, 其中 $d n d B C D E$ 基因组成一个操纵子, 与 $d n d A$ 转录方向相反(如图 3).

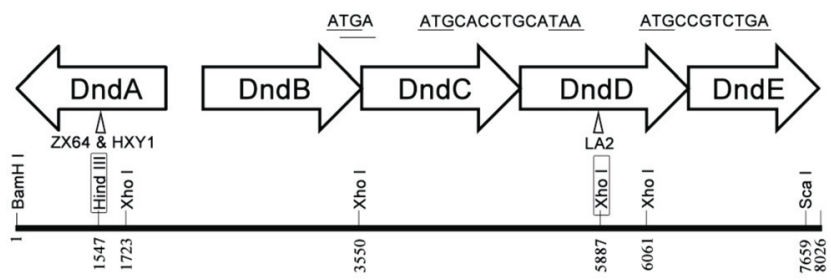

图 $3 d n d$ 基因结构示意图 ${ }^{[7]}$

$d n d B C D E$ 基因组成一个操纵子, 与 $d n d A$ 转录方向相反. 最上面的序列是 推测的 $d n d B C D E$ 相邻两个基因的操纵子, 起始子与终止子用横线标示出 来了

Figure 3 The structure model of $d n d$ gene

$d n d A$ and $d n d B C D E$ are divergently transcribed. The DNA sequences between adjacent genes in the putative $d n d B C D E$ operon are shown at the top, with start and stop codons underlined

这五个 $d n d$ 基因组成的基因簇可以编码五个蛋白, 分别为 DndA, DndB, DndC, DndD, DndE, 微生物正是 利用这五个 Dnd 蛋白来对正常的 DNA 进行磷硫酰化修 饰. 详细了解 DNA 磷硫酰化修饰的机理, 有利于理解 这五个蛋白的功能以及磷硫酰化修饰的 DNA 相对于正 常 DNA 的优越性. 因此, 目前 DNA 磷硫酰化的修饰研 究主要集中于以下三点: (1)五个 Dnd 蛋白的功能及其结 构; (2)五个 Dnd 蛋白在磷硫酰化修饰 DNA 过程中的协 调机制; (3)磷硫酰化修饰 DNA 在生物体内的重要意义.

\section{DNA 磷硫酰化修饰的研究进展}

\section{1 参与 DNA 磷硫酰化修饰的蛋白研究进展}

\subsubsection{DndA 蛋白研究进展}

对 DNA 磷硫酰化修饰相关的酶学功能研究 ${ }^{[26]}$, 并 结合生物信息学分析(dndDB: a database focused on phosphorothioation of the DNA backbone)表明 ${ }^{[11]}$, DndA 与氨基转移酶- $\mathrm{V}$ 保守结构域(Aminotransferase class- $\mathrm{V}$ ) 以及一系列半胱氨酸脱硫酶(Cysteine desulfurase)同源 性很高. 氨基转移酶- $\mathrm{V}$ 结构域见于氨基转移酶和半胱 氨酸脱硫酶等蛋白中. 氨基转移酶的共同特征是在酶的 赖氨酸残基上共价连接有磷酸吡哚醛(Pyridoxal Phosphate, PLP)作为辅酶. 
保守结构域和蛋白的同源比对结果暗示 DndA 可能 是半胱氨酸脱硫酶的同源蛋白, 具有半胱氨酸脱硫酶活 性, 能够催化半胱氨酸产生丙氨酸, 类似于参与到 tRNA 碱基硫修饰中的大肠杆菌 IscS 蛋白, 2007 年邓子 新等 ${ }^{[13]}$ 通过对 DndA 的脱硫酶实验证实了这一揣测. 2012 年吴更等 ${ }^{[27]}$ 解析了来源于变铅青链需菌的活性位 点 C327 突变成 S327 的 DndA 的晶体结构(如图 4). 晶 体中含有 PLP, 并且 PLP 是在蛋白表达过程中结合到蛋 白中的, 这说明该小分子在 DndA 蛋白发挥催化半胱氨 酸脱硫活性时起着重要作用.

然而 2012 年梁晶丹等 ${ }^{[26]}$ 通过统计发现, 并非所有 能够磷硫酰化的微生物都具有 DndA 蛋白, 已经报道的 31 个微生物中, 只有 14 个具有 DndA 蛋白. 与此同时, 他们证明了在缺乏 DndA 的大肠杆菌 DH10B 中, 新转入 的沙门氏菌的 Dnd 基因之所以能够实现异源表达, 完全 是依靠大肠杆菌 DH10B 中的 IscS 脱硫酶充当 DndA 的 角色. IscS 蛋白能够直接参与 DNA 磷硫酰化修饰的过 程, 并且与 DndC 和 DndE 蛋白存在比较强的相互作用.

\subsubsection{DndB 蛋白研究进展}

对 DndB 进行生物信息学分析可知 ${ }^{[11]}$, DndB 蛋白则 可能编码了决定修饰位点特异性的功能, 它的产物与参 与 DNA 修复功能的 ATP 酶和一组转录因子具有同源性, 可能是一类转录调控因子. 研究表明 ${ }^{[7]}$, DndB 蛋白并不 直接参与 DNA 磷硫酰化修饰, 通过对 $\mathrm{dndB}$ 基因的敲除 实验也验证了该预测. 然而尽管 $\mathrm{dndB}$ 基因被敲除后, Dnd 表型仍然能够发生，但是 Dnd 表型的特异性降低了 接近一半, 这也间接表明了 DndB 蛋白在 DNA 磷硫酰化 的修饰过程中起到调节作用.

\subsubsection{DndC 蛋白研究进展}

通过生物信息学分析显示 ${ }^{[11]}$, DndC 可能含有
PAPS_Reductase 保守结构域，并和一系列磷酸腺苷磷 酸硫酸还原酶(phosphoadenosine phosphosulfate reductase) 以及 3'-磷酸腺苷-5'-磷酰硫酸(3'-phosphoadenosine5'-phosphosulfate, PAPS)硫转移酶高度同源，于是推测 其具有 PAPS 还原酶活性. 并且 DndC 含有 $4 \mathrm{Fe}-4 \mathrm{~S}$ 辅因 子, 故也应当具有 ATP 焦磷酸酶活性. 2007 年邓子新 等 ${ }^{[13]}$ 也证实了这一揣测. 因此, DndA 可能将催化半胱 氨酸脱硫产生的活性硫元素传递给已经结合 $\mathrm{Fe}-\mathrm{S}$ 族的 DndC 蛋白，从而参与到下一步的 DNA 磷硫酰化修饰当 中. DndA 能催化 DndC 铁硫簇的装配并激活其 ATP 焦 磷酸酶活性.

\subsubsection{DndD 蛋白研究进展}

生物信息学分析显示 ${ }^{[11]}$, DndD 可能含有 ABC_sbcCD 和 ABC_Rad50 保守结构域. 并且 DndD 蛋 白与 ATP 酶具有同源性. 普遍认为这一蛋白能够水解 ATP 获得能量, 从而对 DNA 进行切割[16]. 2009 年由德 林等 ${ }^{[28]}$ 发现这类蛋白存在一个 Walker A motif. 同时, 他们发现来源于苂光假单胞菌(Pseudomonas fluorescens) Pf0-1 中的 DndD 蛋白的同源蛋白 SpfD 具有 ATP 水解酶的活性, 可能在磷硫酰化修饰过程中, 对 DNA 结构的改变和缺口的形成起着相关作用，但是对这一类 蛋白是否具有 DNA 切割的活性尚不明了, 有待于进一 步研究.

\subsubsection{DndE 蛋白研究进展}

DndE 蛋白的生物信息学分析表明 ${ }^{[11]}$, DndE 蛋白与 一类 NCAIR 合成酶具有比较高的同源性，可能具有 ATP 水解酶的活性 ${ }^{[27]}$. 然而对 DndE 蛋白进行序列 Motif 分析后, 发现其序列中含有(A A V G K TLLIHLHR)序列, 又可能是一类 PAPS 硫转移酶 ${ }^{[29]}$. 正 是 DndE 蛋白生物信息学分析得到的两种可能的功能,
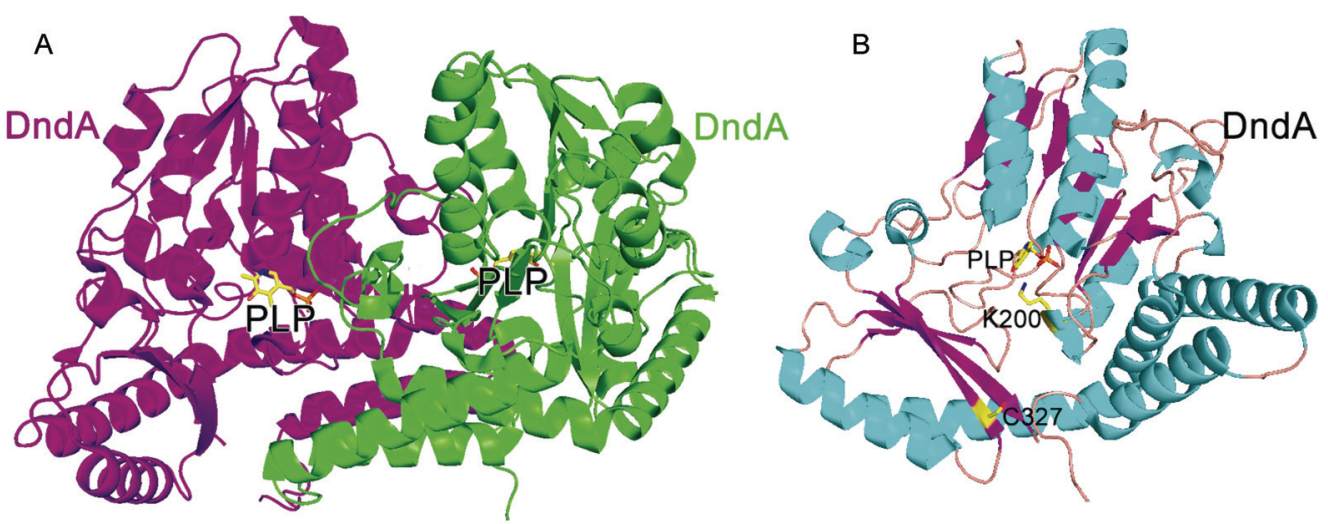

C<smiles>Cc1ncc(COP(=O)(O)O)c(C=O)c1O</smiles>

图 4 来源于变铅青链霉菌的 DndA 晶体结构 ${ }^{[27]}$

A 图显示的是二聚体结构, 两个单体分别用紫红色和绿色标示. 它们结合的辅酶因子 PLP 用球棍模型展示, 其中碳原子用黄色标示, 氮原子用蓝色标示, 氧原子用红色标示, 磷原子用橙色标示. B 图是 DndA 单体的结构, a 螺旋用蓝绿色标示, $\beta$ 折叠用紫红色标示, 环状无规卷曲用粉红色标示, PLP 以及与 DndA 上它共价结合的第 200 位赖氨酸, 连同催化中心 327 位半胱氨酸（作者在研究中突变成了丝氨酸）用球棍模型展示. C 图是 PLP 的分子式

Figure 4 Crystal structure of DndA from Streptomyces lividans

(A) Overall structure of the DndA dimer. The structure is viewed perpendicular to the two-fold axis of the dimer. The different monomers are shown in magenta and green, respectively. Their bound PLP cofactors are presented as sticks, with carbon atoms yellow, nitrogen atoms blue, oxygen atoms red, and phosphorus atoms orange. (B) Structure of a monomer of DndA. The $\alpha$ helices are shown in cyan, $\beta$ sheets are shown in magenta, and loops are shown in pink. PLP and its covalently linked Lys200 of DndA, as well as the catalytic Cys327 (mutated to serine in original study), are shown in stick representation. (C) The chemical structure of PLP 
为进一步开展 DNA 磷硫酰化的修饰的研究带来了困惑. 为了详细了解 DndE 的功能, 2012 年曹春阳等 ${ }^{[30]}$ 解析了 来源于大肠杆菌 B7a 的 DndE 蛋白的同源蛋白 DndE $E_{\mathrm{B} 7 \mathrm{a}-\mathrm{N} 110}$ 的晶体结构(如图 5). 结构表明 DndE 蛋白是 一个四聚体结构, 这种四聚体是由两种不同类型的二聚 体组成. 通过对该蛋白进行结构同源性搜索 (Dali server), 可知 DndE 蛋白可能是一类 DNA 结合蛋白. 苂 光极化偏振分析(Fluorescence polarization assay)和等温 滴定量热法(Isothermal Titration Calorimetry, ITC)实验 结果表明 DndE 蛋白不是一类 PAPS 硫转移酶, 也不是 NCAIR 水解酶, 而是一类具有新颖骨架的缺口 DNA(nicked DNA)结合蛋白. 由此他们推测 DndD 蛋白 切割 DNA 后形成的 nicked DNA, 可能是 DndE 蛋白的 结合底物. DndE 蛋白结合带缺口的双链 DNA(nicked dsDNA), 强于结合碱基序列正常的 dsDNA. 由此得出结 论 DndE 蛋白是一类新颖的结合缺口 DNA 的 DNA 结合 蛋白. 这一发现极大地促进了 DNA 磷硫酰化修饰的研究.

\section{2 磷硫酰化修饰 DNA 的结构预测与功能研究}

3.2.1 $R_{p}$ 型磷硫酰化修饰的 DNA 在构象上趋于不稳定 尽管在早期人们对于硫修饰的反义寡核苷酸进行 了详细的结构分析以及动力学模拟, 但是只局限于人工 合成的硫修饰 DNA 以及硫修饰的 DNA 与 RNA 形成的 杂交体. 随着 DNA 磷硫酰化修饰的发现, 生物体内磷 硫酰化修饰 DNA 形成的唯一的 $R_{p}$ 构象越来越引起人们 的关注. 为什么生物体只选择 $R_{p}$ 构象的 DNA 作为磷硫 酰化修饰的结果, 而不选择 $S_{p}$ 构象呢? 针对这一问题, 赵一雷等 ${ }^{[31]}$ 首次通过量子力学(quantum mechanics)理 论, 从能量的角度计算出生物体内 $R_{p}$ 型构象的磷硫酰 化修饰 DNA 在能量上比序列正常的没有修饰的 DNA 并不具有优势, $R_{p}$ 修饰使得 B-型 DNA 的构象稳定性变 得稍差. 生物体内磷硫酰化修饰 DNA 的构象专一性-不
稳定性之间的关联可能反映的是其结构一功能之间的关 系, 但是这种推算仍然有待于 $R_{p}$ 型磷硫酰化修饰 DNA 结构的验证. 因此表征出磷硫酰化修饰 DNA 的结构成 为今后研究的重中之重.

\subsection{2 磷硫酰化修饰的 DNA 具有抗氧化性}

我们知道, 生物往往需要有氧代谢来高效供能. 然 而, 有氧代谢又常常伴生过氧化物、超氧化物、羟基自 由基等，这会对蛋白质、DNA 等生物大分子造成氧化损 伤. 生物进化出多种机制来清除这些氧化剂, 如谷胱甘 肽、过氧化物酶、超氧化物歧化酶等. 最近研究表明 ${ }^{[32]}$, 硫修饰的 DNA 在体外能被过氧乙酸或双氧水氧化. 磷 硫修饰的 DNA 与多种过氧化物发生氧化还原反应, 或 使 DNA 断裂，或发生硫氧互换，将磷硫修饰的 DNA 氧 化成正常 DNA. 因此可以预测磷硫修饰的 DNA 能够抵 抗有氧代谢过程中产生的过氧化物带给 DNA 的氧化损 伤. 作者同时指出, 这种抗氧化性, 很可能是细菌在早 期生命进化过程中保护自身 DNA 的一种方式，因此可 以被看作生物进化史上的活化石.

\section{4 展望}

\subsection{DNA 磷硫酰化修饰蛋白的结构研究仍有挑战}

截至目前, 参与 DNA 骨架磷硫修饰的蛋白, 由于 存在如下问题: 大部分不易可溶表达，导致纯化困难、 得不到正确折叠的蛋白等, 目前 DndB、DndC、DndD 的结构信息仍然不能很快被解析. 对于已经解析出结构 的 DndA 和 DndE 蛋白，还存在以下疑问: DndA 蛋白的 活性位点处于结构比较刚性的 $\beta$-折叠上, 如何实现硫转 移值得进一步研究; DndE 蛋白与 DNA 的结合比较弱, 如何有效识别 DNA 的 nicking 位点? 两个蛋白在行使 相关功能时构象发生了怎样的改变? 等等. 因此, 相关 蛋白的结构问题是研究 DNA 磷硫修饰机制的瓶颈之一.
A

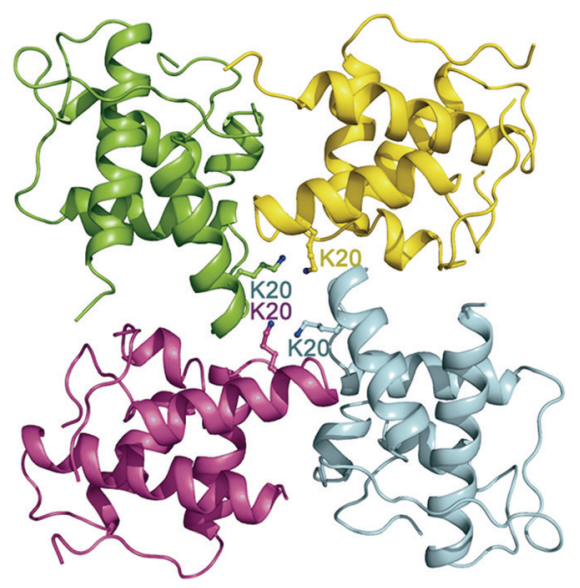

B

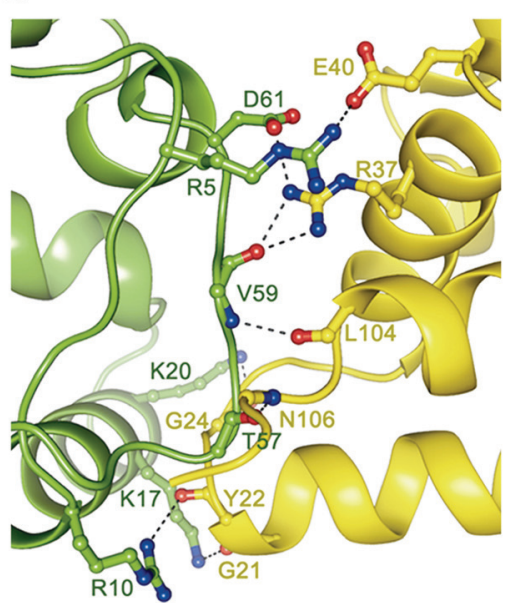

C

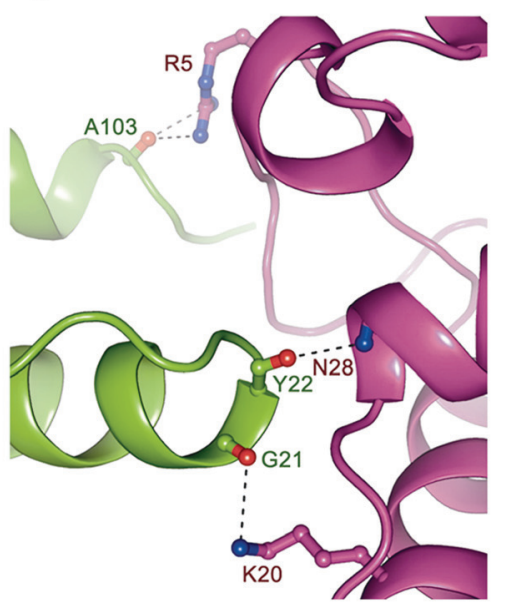

图 5 DndE 结构 ${ }^{[30]}$

(A) DndE $E_{\mathrm{B} 7 \mathrm{a}-\mathrm{N} 110}$ 四聚体的飘带图, 单体 $\mathrm{A}$ 用绿色标示, $\mathrm{E}$ 用紫色标示, C 用品蓝标示, $\mathrm{M}$ 用黄色标示. (B, C)A-M 单体之间, 以及 A-E 单体之间的相互作用 Figure 5 DndE structure

(A) Ribbon diagram of DndE $\mathrm{B}_{\mathrm{B}-\mathrm{a} 110}$ tetramer, monomer $\mathrm{A}$ is shown in green, $\mathrm{E}$ in purple, $\mathrm{C}$ in royal blue and $\mathrm{M}$ in yellow. (B, C) Interfaces between $\mathrm{A}-\mathrm{M}$ monomers and between A-E monomers 


\subsection{DNA 磷硫酰化修饰机理仍不清楚}

虽然参与 DNA 磷硫酰化的蛋白 DndA 和 DndE 的 结构研究获得进展, 磷硫修饰的 DNA 在功能上作为氧 化剂也得到证实, 但 DNA 磷硫修饰具体机制仍然是个 谜团. 比如, 在磷硫酰化过程中缺口 DNA 是如何形成 的, 参与 DNA 磷硫修饰的 5 个蛋白如何协同进行 DNA 磷硫酰化修饰, 磷硫酰化修饰之后的 DNA 的三维结构 及其动力学有何改变等等. 这些问题仍有待进一步研究.

\subsection{DNA 磷硫酰化研究或许有助于人类健康}

与人类疾病相关的很多病原菌也证实了 Dnd 表型 的存在 ${ }^{[34 ~ 37]}$. 因此研究 DNA 磷硫酰化机制, 可能有助 于人类通过干扰微生物 “自我硫修饰” 以改造病菌, 从 而减少病菌对人类的危害. 同时, 通过 “基因药物”, 对 癌症、艾滋病患者的 DNA 进行 “人工修饰”，或许可 以达到治疗疾病的目的.

\section{作者简介}

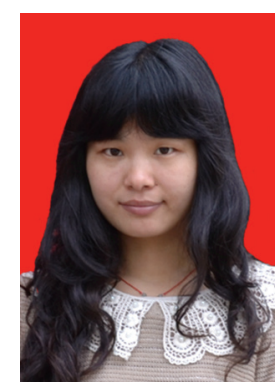

胡中培, 女, 华中师范大学和中科院上海有机所 2010 级 联合培养在读硕士研究生, 主要研究方向为磷硫酰化修饰 DNA 的结构与机理.

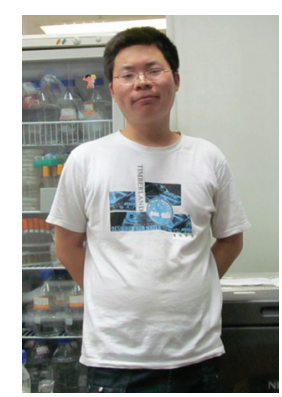

王呈坤, 男, 中国科学院上海有机化学研究所 2008 级在 读博士研究生, 主要研究方向为磷硫酰化修饰 DNA 相关的 Dnd 蛋白的结构与功能.

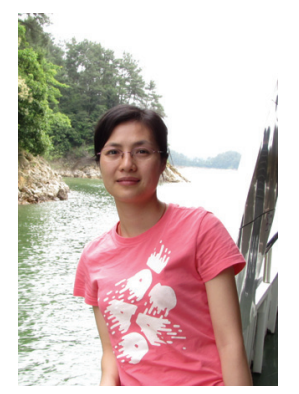

蓝文贤, 女, 1977 年 9 月生. 1999 年本科毕业于华中师范 大学化学系, 2002 年硕士毕业于华中师范大学化学系, 研究方
向为无机化学; 2007 年 6 月博士毕业于中国科学院武汉物理与 数学研究所, 研究方向为利用核磁共振技术研究生物大分子 结构与功能关系. 2007 年 7 月至 2008 年 7 月在中国科学院武 汉物理与数学研究所任研究助理, 继续开发核磁共振新技术 应用于生物分子大结构与动力学特征确定. 2008 年 8 月起在中 国科学院上海有机化学研究所 “百人计划” 研究员曹春阳课 题组担任助理研究员, 研究方向为利用 NMR 技术开展蛋白质 与核酸溶液结构与功能研究.

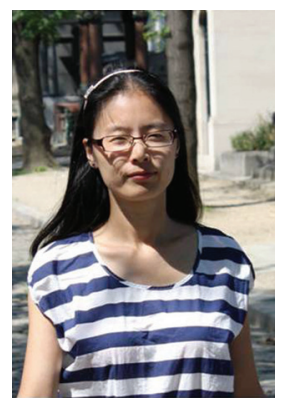

李芳, 女, 1979 年 11 月出生. 2002 年本科毕业于武汉大学 化学系, 2008 年博士毕业于中国科学院武汉物理与数学研究 所无线电物理专业. 现任华中师范大学讲师. 主要研究方向 为: 核磁共振方法及应用研究, 包括小分子与大分子的相互 作用, 化学反应过程的动态监测, 蛋白质的结构和功能, 毒 理、病理生理及疾病发生和发展过程的代谢组学研究.

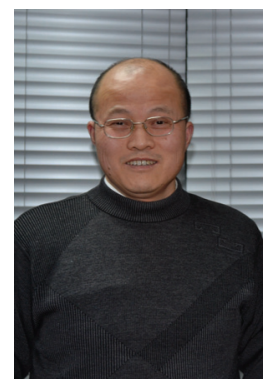

曹春阳, 男, 1970 年 8 月出生. 2001 年博士毕业于中国科 学院上海有机化学研究所, 随后在美国约翰霍普金斯大学医 学院做博士后与研究助理, 2005 年 12 月至 2006 年 08 月, 转 至美国 Salk 生物研究院结构生物学中心做助理研究员. 现任 中国科学院上海有机化学研究所 “百人计划” 研究员, 是上海 市 “浦江计划” 获得者. 研究方向: 以健康与疾病导向的、以 NMR 为主要技术手段的化学生物学与结构生物学. 内容包括: 1.蛋白质与核酸特异性相互作用机制研究: A)神经元千细胞发 育在小 dsRNA 介导下抑制与激活机制研究; B) DNA 甲基化损 伤与修复机制研究; C) DNA 骨架磷硫修饰机制研究; D) HIV 病毒感染与 DNA 碱基脱氨基化机制研究. 2. 蛋白质与蛋白质 相互作用机制研究: A)蛋白质有效运输机制研究(ESCRT 体 系); B)癌症发生与组蛋白修饰. 3. 基于核磁共振波谱学的蛋白 质高效表达新技术新方法研究.

\section{References}

[1] Dai, J. H. J. Theor. Biol. 2012, 310, 249.

[2] Deng, Z. X. China Basic Science 2008, 10, 17. (邓子新，中国基础 科学, 2008, 10, 17.)

[3] Eckstein, F.; Gish, G. Trends Biochem. Sci. 1989, 14, 97.

[4] Wang, L. R.; Chen, S.; Xu, T. G.; Taghizadeh, K.; Wishnok, J. S.; Zhou, X. F.; You, D. L.; Deng, Z. X.; Dedon, P. C. Nat. Chem. Biol. 2007, 3, 709 . 
[5] Xu, T. G.; Yao, F.; Zhou, X. F.; Deng, Z. X.; You, D. L. Nucleic Acids Res. 2010, 38, 7133.

[6] Zhou, X. F.; Deng, Z. X.; Firmin, J. L.; Hopwood, D. A.; Kieser, T. Nucleic Acids Res. 1988, 16, 4341.

[7] Zhou, X. F.; He, X. Y.; Liang, J. D.; Li, A. Y.; Xu, T. G.; Kieser, T.; Helmann, J. D.; Deng, Z. X. Mol. Microbiol. 2005, 57, 1428.

[8] Ra, T.; Weaden, J.; Dyson, P. FEMS Microbiol. Lett. 1992, 75, 247.

[9] Evans, M.; Dyson, P. Trends Genet. 1993, 9, 72.

[10] Ray, T.; Mills, A.; Dyson, P. Electrophoresis 1995, 16, 888.

[11] Liang, J. D. Ph.D. Dissertation, Shanghai Jiaotong University, Shanghai, 2007. (梁晶丹, 博士论文, 上海交通大学, 上海, 2007.)

[12] Wang, L. R. Ph.D. Dissertation, Shanghai Jiaotong University, Shanghai, 2007. (王连荣, 博士论文, 上海交通大学, 上海, 2007.)

[13] You, D. L.; Wang, L. R.; Yao, F.; Zhou, X. F.; Deng, Z. X. Biochemistry 2007, 46, 6126.

[14] He, X. Y.; Ou, H. Y.; Yu, Q.; Zhou, X. F.; Wu, J.; Liang, J. D.; Zhang, W.; Rajakumar, K.; Deng, Z. X. Mol. Microbiol. 2007, 65, 1034.

[15] Liang, J. D.; Wang, Z. J.; He, X. Y.; Li, J. L.; Zhou, X. F.; Deng, Z. X. Nucleic Acids Res. 2007, 35, 2944

[16] Wang, L. R.; Chen, S.; Vergin, K. L.; Giovannoni, S. J.; Chan, S. W.; DeMott, M. S.; Taghizadeh, K.; Cordero, O. X.; Cutler, M.; Timberlake, S.; Alm, E. J.; Polz, M. F.; Pinhassi, J.; Deng, Z. X.; Dedon, P. C. Proc. Natl. Acad. Sci. U. S. A. 2011, 108, 2963.

[17] Warren, R. A. Annu. Rev. Microbiol. 1980, 34, 137.

[18] McClelland, M.; Nelson, M.; Raschke, E. Nucleic Acids Res. 1994, 22, 3640 .

[19] Dyson, P.; Evans, M. Nucleic Acids Res. 1998, 26, 1248.

[20] Lauhon, C. T.; Kambampati, R. J. Biol. Chem. 2000, 275, 20096.

[21] Liesegang, A.; Tschape, H. Int. J. Med. Microbiol. 2002, 291, 645.

[22] Koort, J. M.; Lukinmaa, S.; Rantala, M.; Unkila, E.; Siitonen, A. J. Clin. Microbiol. 2002, 40, 3497.

[23] Silbert, S.; Boyken, L.; Hollis, R. J.; Pfaller, M. A. Diagn. Micr.
Infec. Dis. 2003, 47, 619.

[24] Murase, T.; Nagato, M.; Shirota, K.; Katoh, H.; Otsuki, K. Vet. Microbiol. 2004, 99, 139.

[25] Xu, T. G. Ph.D. Dissertation, Shanghai Jiaotong University, Shanghai, 2008. (徐铁刚, 博士论文, 上海交通大学, 上海, 2007.)

[26] An, X. H.; Xiong, W.; Yang, Y.; Li, F. H.; Zhou, X. F.; Wang, Z. J.; Deng, Z. X.; Liang, J. D. PLoS One 2012, 7, e51265.

[27] Chen, F. K.; Zhang, Z. Y.; Lin, K.; Qian, T. L.; Zhang, Y.; You, D.; He, X. Y.; Wang, Z. J.; Liang, J. D.; Deng, Z. X.; Wu, G. PLoS One 2012, 7, e36635.

[28] Yao, F.; Xu, T. G.; Zhou, X. F.; Deng, Z. X.; You, D. L. FEBS Lett. 2009, 583, 729 .

[29] Lundblad, J. R.; Laurance, M.; Goodman, R. H. Mol. Endocrinol. 1996, 10, 607.

[30] Hu, W.; Wang, C. K.; Liang, J. D.; Zhang, T. L.; Hu, Z. P.; Wang, Z. J.; Lan, W. X.; Li, F.; Wu, H. M.; Ding, J. P.; Wu, G.; Deng, Z. X.; Cao, C. Y. Cell Res. 2012, 22, 1203.

[31] Zhang, Y. C.; Liang, J.; Lian, P.; Han, Y. W.; Chen, Y. F.; Bai, L. Q.; Wang, Z. J.; Liang, J. D.; Deng, Z. X.; Zhao, Y. L. J. Phys. Chem. B 2012, 116, 10639.

[32] Xie, X. Q.; Liang, J. D.; Pu, T. N.; Xu, F.; Yao, F.; Yang, Y.; Zhao, Y. L.; You, D. L.; Zhou, X. F.; Deng, Z. X.; Wang, Z. J. Nucleic Acids Res. 2012, 40, 9115.

[33] Eckstein, F. Nat. Chem. Biol. 2007, 3, 689.

[34] Romling, U.; Tummler, B. J. Clin. Microbiol. 2000, 38, 464.

[35] Marshall, S.; Clark, C. G.; Wang, G.; Mulvey, M.; Kelly, M. T.; Johnson, W. M. J. Clin. Microbiol. 1999, 37, 2473.

[36] Zhang, Y. S.; Yakrus, M. A.; Graviss, E. A.; Williams-Bouyer, N.; Turenne, C.; Kabani, A.; Wallace, R. J. J. Clin. Microbiol. 2004, 42, 5582 .

[37] Wong, H. C.; Chen, S. Y.; Chen, M. Y.; Oliver, J. D.; Hor, L. I.; Tsai, W. C. Appl. Environ. Microbiol. 2004, 70, 5153.

(Cheng, B.; Lu, Z.) 